\title{
Control of a Permanent Magnet Synchronous Motor in Simulink
}

\author{
Mihály KATONA, ${ }^{1}$ Péter KISS ${ }^{2}$ \\ ${ }^{1}$ Budapest University of Technology and Economics. Budapest, Hungary, katona.mihaly@edu.bme.hu \\ ${ }^{2}$ Budapesti University of Technology and Economics. Budapest, Hungary, kiss.peter@vik.bme.hu
}

\begin{abstract}
Nowadays, before the era of modern Steer-by-wire steering systems, the most widely used steering technology is Electric Power Steering (EPS). This paper contains the developing of a Permanent Magnet Synchronous Motor (PMSM) control circuit for EPS systems, in Matlab Simulink environment. The mathematical model of the Permanent Magnet Synchronous Motor was created via the four equations that represent the relation between the fluxes, voltages and currents in d-q reference frame and the motor torque equation. Mathematical transformations are required to generate the equivalent input values of the model from analog input waves. In this way, the embedded software is able to communicate with the motor through the analog input and output signals. The control model was also tested in a physically implemented system. The control software is executed on a dSpace AutoBox hardware. The output interface block creates the output phase voltages specified by the control module, and the input interface block allows the phase currents generated by the output voltage to be measured back.
\end{abstract}

Keywords: synchronous motor, motor control, electric power steering, hardware-in-the-loop.

\section{Introduction}

One of the most widely used motor types in vehicles is the permanent magnet synchronous motor. In electric power steering systems, it is the most convenient because of the wide range of revolution speeds and torque range. An important part of the steering system is the motor control because during operation a seemingly insignificant event, like a driving over a road bump, can create a significant load that appears as a transient in the control system. One practice used in industrial environments is the hardwarein-the-loop test for testing the control software. For a company to maintain market advantage the cost of the development of such a system has to be kept at minimum. Modern computer technology and the implementation of the already formulated mathematical models provide an opportunity that means it is not necessary to physically implement the system to test the drive chain and the motor design. The construction of mathematical models in a Simulink environment provides an opportunity for the proper operation of the designed electric motor to be approached during the product development process. This frees up the project from significant expenditures, thus helping its economic competitiveness. The aim of the modelling is to approximate the predefined output parameters, mainly of the magnitude of the torque, the ripple, the harmonic content of the motor current. The regulatory circuit can be examined by so-called hardware-in-the-loop (HIL) tests. In this step the program code is loaded into the microprocessor unit of a control circuit built into an already established test system, where its operation is tested with measurements by physical sensors. A practical implementation in a dSpace environment was summarized in the study of Y. Huangfu and W. Liu. [1] Their results support the success of the implementation and the need for a theoretical summary of the process, which will be explained below. 


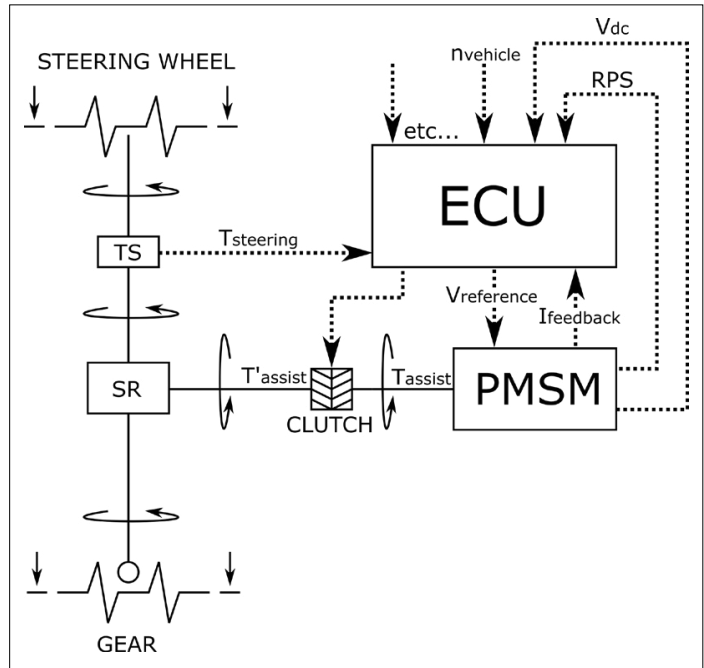

Figure 1. Scheme of an Electric Power Steering system. [3]

\section{Electric power steering}

Steering is the term applied to the collection of components, linkages, which will allow a vessel or vehicle to follow the desired course. An EPS system shown in Figure 1 includes mechanical, electrical and control subsystems. One of the main parts of the EPS system is the electric control subsystem, which receives the signals collected by sensors. Using the collected data, such as vehicle speed, steering angle and steering torque, the Electric Control Unit (ECU) controls the assistant motor to give the required steering torque. The principal of the operation can be described as follows: the steering wheel turns, a steering torque is generated via a shaft, which turns the steering rack. As the steering rack changes its position the wheels turn proportionately, which causes change in the torque which is necessary for steering. In order to assist the driver and provide a good steering experience, a certain amount of torque is added by the assistant servo motor.[2]

\section{Implementation of the mathematical model}

\subsection{Direct and quadrant parameters}

A reasonable choice is to use a coordinate system, where the direct component (d) is fixed to the pole flux vector of the rotor, relative to which the quadrant component (q) differs by an electrical angle of $90^{\circ}$. In this case, it is not necessary to use trigonometric equations to describe the motor. During the modelling, the mathematical equations describe the operation of the control circuit by d-q components, but during the hardware-in-the-loop (HIL) test and in the finished product, the input parameters of the program code are measured back from the physical world, which are recorded as timewise analog quantities. It is necessary to transform the measurements into the $d-q$ coordinate system.

In case of Clarke transformation, the a-b-c components of the measured three-phase quantities fall into the $\alpha-\beta-0$ reference frame. [4]

$$
\left[\begin{array}{l}
f_{\alpha} \\
f_{\beta} \\
f_{0}
\end{array}\right]=\left[\begin{array}{ccc}
\frac{2}{3} & -\frac{1}{3} & -\frac{1}{3} \\
0 & \frac{1}{\sqrt{3}} & -\frac{1}{\sqrt{3}} \\
\frac{1}{3} & \frac{1}{3} & \frac{1}{3}
\end{array}\right] \cdot\left[\begin{array}{l}
f_{a} \\
f_{b} \\
f_{c}
\end{array}\right]
$$

$$
\left[\begin{array}{l}
f_{a} \\
f_{b} \\
f_{c}
\end{array}\right]=\left[\begin{array}{ccc}
1 & 0 & 1 \\
-\frac{1}{2} & \frac{\sqrt{3}}{2} & 1 \\
-\frac{1}{2} & -\frac{\sqrt{3}}{2} & 1
\end{array}\right] \cdot\left[\begin{array}{l}
f_{\alpha} \\
f_{\beta} \\
f_{0}
\end{array}\right]
$$

In case of Park transformation, the $\alpha-\beta-0$ reference frame is transformed into a fixed coordinate system consisting of d-q-0 components. [5]

$$
\begin{aligned}
& {\left[\begin{array}{l}
f_{d} \\
f_{q} \\
f_{0}
\end{array}\right]=\left[\begin{array}{ccc}
\cos \left(\varphi_{e}\right) & \sin \left(\varphi_{e}\right) & 0 \\
-\sin \left(\varphi_{e}\right) & \cos \left(\varphi_{e}\right) & 0 \\
0 & 0 & 1
\end{array}\right] \cdot\left[\begin{array}{l}
f_{\alpha} \\
f_{\beta} \\
f_{0}
\end{array}\right]} \\
& {\left[\begin{array}{l}
f_{\alpha} \\
f_{\beta} \\
f_{0}
\end{array}\right]=\left[\begin{array}{ccc}
\cos \left(\varphi_{e}\right) & -\sin \left(\varphi_{e}\right) & 0 \\
\sin \left(\varphi_{e}\right) & \cos \left(\varphi_{e}\right) & 0 \\
0 & 0 & 1
\end{array}\right] \cdot\left[\begin{array}{c}
f_{d} \\
f_{q} \\
f_{0}
\end{array}\right]}
\end{aligned}
$$

where $\varphi_{\mathrm{e}}$ is the rotor position in electrical angle [rad].

\subsection{Electrical and mechanical behaviour}

The sinusoidal distribution of the magnetic field ideally generated by the permanent magnets of the synchronous machine can be described by the pole flux vector, i.e., it can be said that the flux of the rotor is equal to the pole flux vector. The stator terminal voltage can be described as the sum of the pole voltage and the voltage across the winding. [6]

$$
\begin{aligned}
& \boldsymbol{U}_{\boldsymbol{k}}=R \boldsymbol{i}+\boldsymbol{L} \frac{d \boldsymbol{i}}{d t}+j \omega_{e} \boldsymbol{L i}+j \omega_{e} \boldsymbol{\Psi}_{\boldsymbol{p}} \\
& \omega_{e}=p \omega_{m}
\end{aligned}
$$

where,

$\omega_{e} \quad$ rotor electrical rotation speed $[\mathrm{rad} / \mathrm{s}]$

$\omega_{m}$ rotor mechanical rotation speed [rad/s]

$p \quad$ rotor pole pair number [p.u.] [1] 
The real part of equation (5) gives the direct (d) while the imaginary part gives the quadrant (q) components. It is worth expressing the currents from the mentioned equations, because during the simulation the control signal will be the voltage while the feedback is provided by the current.

$$
\left[\begin{array}{c}
\frac{i_{q}}{d t} \\
\frac{i_{d}}{d t}
\end{array}\right]=\left[\begin{array}{cc}
-\frac{R}{L_{d}} & \frac{\omega_{e} L_{q}}{L_{d}} \\
-\frac{\omega_{e} L_{d}}{L_{q}} & -\frac{R}{L_{q}}
\end{array}\right] \cdot\left[\begin{array}{l}
i_{d} \\
i_{q}
\end{array}\right]+\left[\begin{array}{cc}
\frac{1}{L_{d}} & 0 \\
0 & \frac{1}{L_{q}}
\end{array}\right] \cdot\left[\begin{array}{l}
U_{d} \\
U_{q}
\end{array}\right]+\left[\begin{array}{c}
0 \\
-\frac{\omega_{e} \Psi_{p}}{L_{q}}
\end{array}\right]
$$

where,

$$
\begin{array}{ll}
i_{d}, i_{q} & \text { current of the stator }[A] \\
L_{d}, L_{q} & \text { inductance of the stator }[H] \\
U_{d}, U_{q} & \text { terminal voltage of the stator [V] } \\
R & \text { resistance of the stator }[\Omega]
\end{array}
$$

The torque depends on the pole flux and the current vector described by equation (8).

$$
M=\frac{3}{2} p|\Psi \times \boldsymbol{i}|=\frac{3}{2} p\left(\Psi_{p} i_{q}+\left(L_{q}-L_{d}\right) i_{q} i_{d}\right)
$$

where,

$\mathrm{M}$ electrical torque of the motor [Nm]

$\Psi_{p} \quad$ pole flux of the rotor [Vs]

The rotor speed can be calculated by the mechanical equation of a parallel spring and a mass.

$$
M(\varphi)=\Theta \ddot{\varphi}+D \dot{\varphi}+K \varphi
$$

where,

$\theta$ moment of inertia $\left[\mathrm{kgm}^{2}\right]$

D damping factor [Nms]

$\mathrm{K}$ torsion factor [Nm/rad]

By implementing the equations described in this chapter and using appropriate transformations, the PMSM model can be constructed.

\section{Sinusoidal pulse width modulation}

"Sinusoidal pulse-width modulation (sPWM) technique is one of the simplest carrier-based modulation methods for the control [...] The sPWM is a familiar shaping technique in the field of power electronics where a high frequency triangular carrier signal is compared to a sinusoidal modulation signal [...] The number of pulses per cycle is decided by the ratio of the triangular carrier frequency to that of modulating sinusoidal frequency." [7]

During the modelling a two-level inverter was created where one bridge can be connected to either the positive or the negative rail. Apart from the offset and losses, the maximum of the motor phase voltage can be half the DC voltage of the inverter.

$$
U_{e}=\frac{U_{d c}}{2}
$$

where,
$\mathrm{U}_{\mathrm{dc}} \quad$ DC inner voltage of the inverter [V]
$\mathrm{U}_{\mathrm{e}} \quad$ DC rail voltage of the inverter [V]

In the case of a three-phase symmetrical excitation, the impedance of each phase coil is the same, $\left|\mathbf{Z}_{\mathbf{a}}\right|=\left|\mathbf{Z}_{\mathbf{b}}\right|=\left|\mathbf{Z}_{\mathbf{c}}\right|$. Then the sum of the phase voltages is also zero $\mathrm{U}_{\mathrm{aY}}+\mathrm{U}_{\mathrm{bY}}+\mathrm{U}_{\mathrm{cY}}=0$. The voltage at the star point relative to ground is equal to the zero-order voltage described by equation (11) if two bridge branches are connected to a positive rail. [8]

$$
U_{0}=\frac{U_{a}+U_{b}+U_{c}}{3}=\frac{U_{e}+U_{e}+\left(-U_{e}\right)}{3}
$$

where,

$$
\begin{array}{ll}
\mathrm{U}_{0} & \text { zero order voltage [V] } \\
\mathrm{U}_{\mathrm{a}}, \mathrm{U}_{\mathrm{b}}, \mathrm{U}_{\mathrm{c}} & \text { phase voltages [V] }
\end{array}
$$

Based on the latter the maximum voltage of a phase:

$$
U_{f 0}=U_{a}+U_{0}=\frac{1}{3} U_{e}+U_{e}=\frac{4}{3} U_{e}
$$

Due to the design of the inverter, two transistors on three bridges define 8 different switching states. If the switching states are examined in a stationary coordinate system, where a 3-bit tag represents the different switching states, with 0 denoting the bridge is connected to negative rail, whilst 1 denotes the positive state. In order to facilitate the control, it is worth setting an inner circuit to limit the voltage. It can be clearly seen that the absolute value of the output voltage vector is equal to the radius of the inner circle, which is the height of the sector. This can be calculated by the height formula of a triangle.

$$
r U_{e}=\frac{1}{2} a \cdot \cot \frac{\pi}{n}=\frac{1}{2} \cdot \cot \frac{\pi}{6}=\frac{\sqrt{3}}{2} U_{e}
$$

where,

$r \quad$ radius of the inscribed circle [p.u.]

a length of one side of the hexagon [p.u.]

$\mathrm{n}$ number of sides of the hexagon [p.u.]

During the coding of the model, it is important to determine the maximum of the phase voltage which is described by equation (14).

$$
U_{f \mid \max }=U_{f 0} r=\frac{4}{3} \cdot \frac{\sqrt{3}}{2} \cdot \frac{1}{2} U_{d c}=\frac{1}{\sqrt{3}} U_{d c}
$$

In the model, the output signals of the inverter vary between $\pm U_{f \mid \text { max }}$ Of the three pulse width modulation types - edge, centre and adaptive - the implementation of the first was done. In the case of simulations running only in a digital environment, no significant difference in the results was 
observed. In the case of the HIL test, it is advisable to use adaptive fitting depending on the current measurement method. In the case of edge-aligned modulation, the carrier signal is a high-frequency sawtooth signal $(16-20 \mathrm{kHz})$ while the modulator is a sine wave.

$$
C=\left\{\begin{array}{l}
1, \text { ha } J_{m} \leq J_{v} \\
0, h a J_{m}>J_{v}
\end{array}, \text { ahol } J_{m}, J_{v} \in[0,1]\right.
$$

where,

C control signal of the inverter bridges [p.u.]

Jm modulator signal [p.u.]

$\mathrm{J}_{\mathrm{v}} \quad$ carrier signal [p.u.]

The output frequency and amplitude of the control signal is dependent on the frequency and the amplitude of the carrier signal, there is a linear relationship between them.

The control circuit is designed with a simple three-level topology with a speed, torque and current regulator connected in series. These are PI type regulators tuned by the Good Gain method that was developed by Finn Haugen. [9]

\section{Results}

Figure 2 shows the torque response of the control system to the simulated load. The latter is a combination of the torque derived from steering, road bumps and mechanical losses of the steering system. This figure shows that the control circuit explained beforehand works as expected, because the torque response is fast and accurate. Furthermore, this result ensures that a validation process can be started, as the mechanical losses of the HIL system are known. Figure 3 shows the differential torque that can be perceptiblefor the driver without damping. The higher spikes can be interpretable as a vehicle crossing a railway and the lowers are simple steering for example. One goal of a whole development process is to decrease those spikes so as to enhance the driving experience.

As the results show, the implementation of the mathematical model in Simulink environment is an effective method to simulate the behaviour of a steering system, especially the control circuit.

It is a widely used solution in industrial practice to have a gear transmission between the motor shaft and the driven shaft. This is to solve the problem as the motor torque is not enough. In this case, the driven torque can be increased by expanding the rotation speed range and selecting the appropriate transmission. The former can be increased by using field-weakening mode. The torque-rotation speed characteristic then can be simulated. The result is shown in Figure 4 . From the mentioned characteristic the required gear ratio or, in the case of given transmission, the applicability of the chosen electric motor can be deduced. Furthermore, it is possible to use the results to refine the design parameters of the construction.

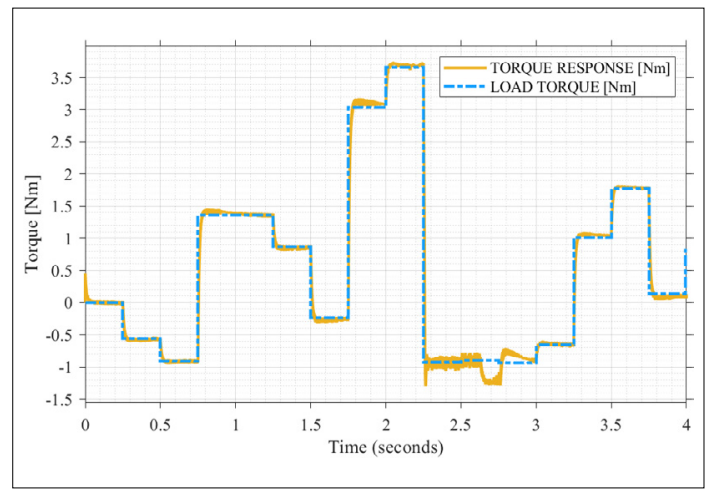

Figure 2. Torque response of the control system.

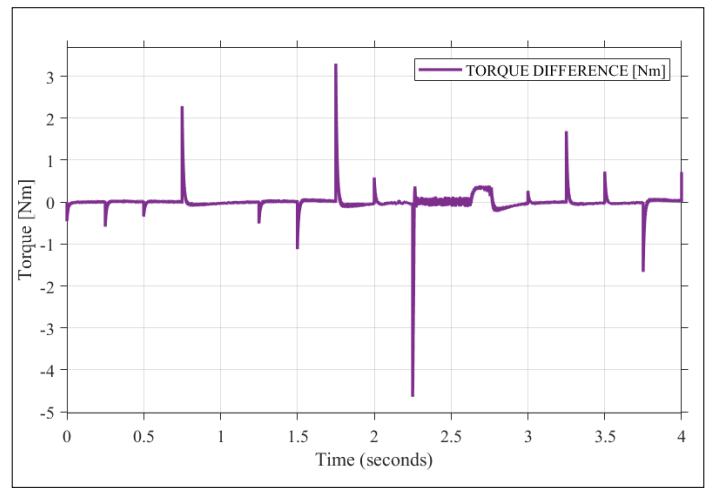

Figure 3. Aifferential torque of the control system.

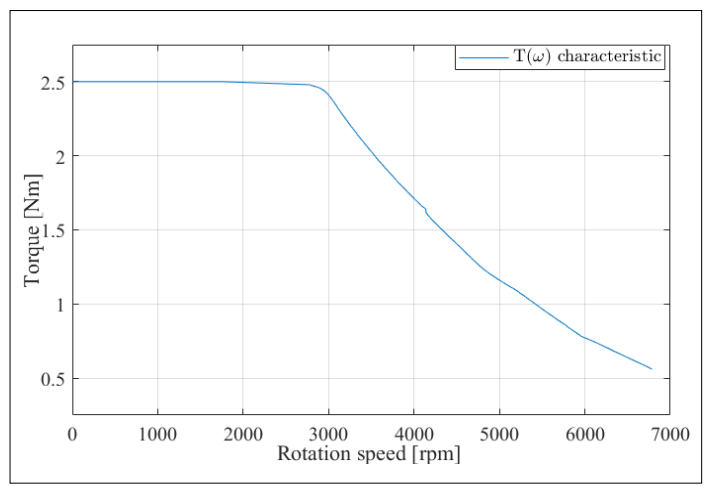

Figure 4. $T(\omega)$ characteristic 


\section{Acknowledgments}

I would like to thank to Árpád Handler and Tibor Vajsz Phd. for their help in the field of drive regulation! The research reported in this paper and carried out at the BME has been supported by the NRDI Fund based on the charter of bolster issued by the NRDI Office under the auspices of the Ministry for Innovation and Technology.

\section{References}

[1] Huangfu Y., Liu W.: Rapid Development Controller Design for PMSM Based on Hardware-in-the-loop. $5^{\text {th }}$ IEEE Conference on Industrial Electronics and Applications, Taichung, 2010. 1963-1966. https://doi.org/10.1109/ICIEA.2010.5515537

[2] Hao C., Yali Y., Ruoping Z.: Study on Electric Power Steering System Based on Adams, Shanghai University of Engineering Science. Procedia Engineering, 15. (2011) 474-478. https://doi.org/10.1016/j.proeng.2011.08.090

[3] Shaoyun Z., Yi W.: Study of Electric Power Steering System. International Conference on Computer Science and Intelligent Communication, 2015. https://doi.org/10.2991/csic-15.2015.77

[4] [Chakraborty A. K., Bhattachaya B.: Determination of $\alpha, \beta$ and $\gamma$-Components of a Switching State without Clarke Transformation. $2^{\text {nd }}$ International Conference on Control, Instrumentation, Energy \& Communication (CIEC) 2016, 260-264. https://doi.org/10.1109/CIEC.2016.7513764

[5] Pillay P., \& Krishnan R.: Modeling of Permanent Magnet Motor Drives. IEEE Transactions on Indus-trial Electronics, 35/4. (1988) 537-541. https://doi.org/10.1109/41.9176

[6] Vajsz T., Rácz Gy., Számel L.: Novel Modified dtcsvm Method with Better Overload-Capability for Permanent Magnet Synchronous Motor Servo Drives. Periodica Polytechnica, Electrical Engineering and Computer Science, 61. (2017) 253-263. https://doi.org/10.3311/PPee.10428

[7] Vijayakumar K.: Application of Sinusoidal Pulse Width Modulation Based Matrix Converter as Revolutionized Power Electronic Converter. Lecture Notes in Electrical Engineering, 326. 2014.

[8] Schmidt I., Veszprémi K.: Hajtásszabályozások. https://vet.bme.hu/?q=kutatas/tamop/anyagok

[9] Haugen F.: The Good Gain Method for Simple Experimental Tuning of PI Controllers. Modeling, Identification and Control, 33/4. (2012) 141-152.

[10] Kuslits M.: Állandómágneses szinkrongépek modellalapú irányításfejlesztése. Publio Kiadó Kft. 2016. 